\title{
LARGE-SCALE FLOW STRUCTURE IN TURBULENT NONPREMIXED FLAMES UNDER NORMAL- AND LOW-GRAVITY CONDITIONS
}

\author{
N. T. Clemens, C. A. Idicheria and I. G. Boxx \\ Department of Aerospace Engineering \& Engineering Mechanics, The University of Texas at \\ Austin, Austin, TX 78712-1085
}

\section{INTRODUCTION}

It is well known that buoyancy has a major influence on the flow structure of turbulent nonpremixed jet flames. Buoyancy acts by inducing baroclinic torques, which generate largescale vortical structures that can significantly modify the flow field. Furthermore, some suggest that buoyancy can substantially influence the large-scale structure of even nominally momentum-dominated flames, since the low velocity flow outside of the flame will be more susceptible to buoyancy effects. ${ }^{1}$ Even subtle buoyancy effects may be important because changes in the large-scale structure affects the local entrainment and fluctuating strain rate, and hence the structure of the flame. Previous studies that have compared the structure of normaland micro-gravity nonpremixed jet flames note that flames in microgravity are longer and wider than in normal-gravity. ${ }^{2-5}$ This trend was observed for jet flames ranging from laminar to turbulent regimes. Furthermore, imaging of the flames has shown possible evidence of helical instabilities and disturbances starting from the base of the flame in microgravity. In contrast, these characteristics were not observed in normal-gravity.

The objective of the present study is to further advance our knowledge of the effects of weak levels of buoyancy on the structure of transitional and turbulent nonpremixed jet flames. In later studies we will utilize the drop tower facilities at NASA Glenn Research Center (GRC), but the preliminary work described in this paper was conducted using the 1.25 -second drop tower located at the University of Texas at Austin. A more detailed description of these experiments can be found in Idicheria et al. ${ }^{6}$

\section{EXPERIMENTAL APPARATUS/CONDITIONS}

The experiments were conducted using a newly constructed jet flame drop-rig (Fig. 1) that is housed in a standard GRC 2.2 second droptower frame (38"x36"x16"). Piloted ethylene jet flames were studied, which issued from a $1.75 \mathrm{~mm}$ straight tube into quiescent air within the drop box. A premixed methane-air pilot flame was used to ignite the flame and to further forestall flame liftoff. The ethylene and methane were stored in two onboard, $18.3 \mathrm{in}^{3}$ stainless steel pressure vessels. Flow rates were controlled with line pressure regulators upstream of choked micro-metering valves. Line pressures were recorded using pressure transducers installed upstream of the micro-metering valves and read into the onboard computer. Solenoid valves, connected via solid-state relays to the digital I/O card of an onboard computer, were used to start and stop the flow. The onboard computer was a ruggedized Pentium Celeron based PC equipped with frame grabber and data acquisition cards. Flame luminosity was imaged using a progressive scan CCD camera (Pulnix TM-6710) operated at a resolution of 512×145 pixel $^{2}$ and 350 frames per second.

The preliminary data reported here were obtained with the 1.25 -second drop tower at the University of Texas at Austin. The tower is $35 \mathrm{ft}$ tall, with an $8 \mathrm{ft} \times 8 \mathrm{ft}$ cross-section and provides a drop distance of $25 \mathrm{ft}$. The box is decelerated by falling into a $6 \mathrm{ft} \times 4 \mathrm{ft} \times 7 \mathrm{ft}$ container filled with polyurethane foam cubes. Accelerometer data taken during the drops show 
that low-gravity levels of $10-30 \mathrm{mg}$ can be achieved. These relatively high g-levels result from the fact that no drag shield was used. The deceleration levels at impact were about $25 \mathrm{~g}$.

Jet flames at a range of Reynolds numbers were studied as shown in Table 1. The Reynolds number $\left(\operatorname{Re}_{\mathrm{D}}=\mathrm{U}_{0} \mathrm{D} / \mathrm{v}\right)$ is based on the jet exit diameter $D$, jet exit velocity $U_{0}$ and the kinematic viscosity of ethylene at room temperature. Also shown in Table 1 is

\begin{tabular}{|c|c|c|c|c|c|}
\hline \multicolumn{7}{|c|}{ Table 1. Flow conditions. } \\
\hline Case & Fuel & $\mathrm{U}_{0}(\mathrm{~m} / \mathrm{s})$ & $\mathrm{Re}_{\mathrm{D}}$ & $\xi_{\mathrm{L}}(\mathrm{g})$ & $\xi_{\mathrm{L}}(20 \mathrm{mg})$ \\
\hline $\mathrm{I}$ & Ethylene & 12.4 & 2,500 & 8.5 & 2.4 \\
\hline 2 & Ethylene & 24.8 & 5,000 & 6.6 & 1.5 \\
\hline 3 & Ethylene & 37.2 & 7,500 & 4.6 & 1.3 \\
\hline 4 & Ethylene & 52.2 & 10,500 & 3.7 & 1.0 \\
\hline
\end{tabular}
the parameter $\xi_{\mathrm{L}}$, which was used by Becker and Yamazaki ${ }^{7}$ to quantify the effect of buoyancy on the mean entrainment of turbulent jet flames. This buoyancy parameter is defined as $\xi_{\mathrm{L}}=\mathrm{Ri}_{\mathrm{s}}{ }^{1 / 3} \mathrm{~L}_{\mathrm{f}} \mathrm{D}_{\mathrm{s}}$, where $\mathrm{Ri}_{\mathrm{s}}$ is the source Richardson number $\left(\mathrm{Ri}_{\mathrm{s}}=\mathrm{gD}_{\mathrm{s}} / \mathrm{U}_{\mathrm{s}}{ }^{2}\right)$ based on the source diameter $D_{s}=D\left(\rho_{0} / \rho_{\infty}\right)^{1 / 2}$, and source velocity $U_{s}=U_{0}$ for a top-hat velocity profile. $L_{f}$ is the average visible flame length, $g$ is the acceleration due to gravity, $\rho_{0}$ is the jet fluid density and $\rho_{\infty}$ is the ambient density. Becker and Yamazaki ${ }^{8}$ suggest that flames with $\xi_{\mathcal{L}}<1$ are momentum dominated. Interestingly, this table shows that even under our milli-g conditions, the lower Reynolds number flames may exhibit some buoyancy effects.

\section{RESULTS AND DISCUSSION}

Figure 2 shows sample image sequences of the flame startup for low- and normal-gravity conditions at an exit Reynolds number of 7500 . The jet was started only after the drop was initiated. The time to reach steady state was investigated quantitatively by analyzing the instantaneous flame tip location as a function of time. Figure 3 shows the flame length variation with time (as obtained from individual frames) for different Reynolds numbers. From these plots it is clearer that the low-gravity flame takes a longer time to reach steady state. Even in the low Reynolds number cases ( 2500 and 5000 ), the difference is only about $200 \mathrm{~ms}$. At the higher Reynolds numbers, the startup transient is nearly the same for normal- and low-g, as the difference is about $100 \mathrm{~ms}$. Also, in all cases the flame is seen to reach a steady state in less than $300 \mathrm{~ms}$.

Figure 4 shows sample steady state sequences for a Reynolds number of 7500 . The lowgravity sequence shows what appears to be evidence of a helical large-scale instability in agreement with Ref. 3 , but a similar structure is not seen at $1 \mathrm{~g}$. The steady state sequences were used to compute mean emission images, as shown in Fig. 5, and from these the mean visible flame length $\left(L_{f}\right)$ was measured. In all of the cases studied, there is little difference in the average visible flame lengths measured under normal- and low-gravity conditions, as shown in Figure 6. The maximum difference was of about $10 \%$ of the flame height at $\operatorname{Re}_{D}=5,000$. Any differences in length and width between flames in normal- and low-gravity conditions are seen to diminish as the flame becomes more momentum dominated.

We also investigated the evolution of the large-scale structures in the flames using volume rendering of image sequences. This technique, discussed by Mungal et al. ${ }^{8}$, gives good visual information on the structure evolution. In this technique a sequence of two-dimensional images ( $x-y)$ is stacked one behind the other along the $z$-axis (time, $t$ ) and a three dimensional volume $(x-y-t)$ is generated. The surface of this $3-D$ model is an isocontour corresponding to the visible flame edge in each image. Volume rendering highlights features that are not immediately 
apparent in the still images or movie sequences. Sample renderings at $R_{D}=2500$ are shown in Figure 7. In these images, convection of large-scale structures appears as wrinkles traveling up and to the right on the surface of the volume. The slope of these wrinkles can be used as a qualitative estimate of the large-scale structure convection velocity. It can be seen that the flame tip in low-gravity (figure 7a) fluctuates at a lower frequency than in normal-gravity (figure 7b); however, in the higher Reynolds number case (figures not presented due to lack of space) we observed that the flame tip oscillations and large-scale structure convection velocities become comparable. All of these observations show the decreasing effect buoyancy has on flame characteristics and behavior, as $\xi_{\mathrm{L}}$ decreases.

\section{FUTURE WORK}

Our future work will be directed at investigating these observations further by utilizing the 2.2 second drop-tower at NASA GRC, which will provide us with purely momentum dominated flames in lower Reynolds numbers. We are also currently working on implementing laser-based diagnostics including Mie scattering and particle image velocimetry to further investigate the large-scale structures and strain-vorticity fields.

\section{ACKNOWLEDGEMENTS}

This work is supported by NASA under cooperative agreement NCC3-677. The authors also wish to thank Dr. Z. G. Yuan of NCMR and Andrew Jenkins of NASA Glenn for their invaluable input into the design and fabrication of the drop-rig.

\section{REFERENCES}

1. Roquemore, W.M., Chen, L.D., Goss, L.P. and Lynn, W.F., Lecture notes in Engineering Vol. 40, SpringerVerlag, pp. 49-63 (1989).

2. Bahadori, M.Y., Stocker, D.P., Vaughan, D.F., Zhou, L. and Edelman, R.B., Modern Developments in Energy, Combustion and Spectroscopy, Pergamon Press, pp. 49-66.

3. Hegde, U., Yuan, Z.G., Stocker, D.P. and Bahadori, M.Y., AIAA paper 2000-0697 (2000).

4. Hegde, U., Yuan, Z.G., Stocker, D.P. and Bahadori, M.Y., Fifth International Microgravity combustion Workshop, May (2000).

5. Hegde, U., Zhou, L., Bahadori, M. Y., Combustion Science \& Technology, Vol. 102, pp. 95-113 (1994).

6. Idicheria, C.A., Boxx, I.G. and Clemens, N.T., AIAA paper 2001-0628 (2001).

7. Becker, H. A. and Yamazaki, S., Combustion and Flame, Vol. 33, pp. 123-149 (1978).

8. Mungal, M.G., Karasso, P.S. and Lozano, A., Combustion Science \& Technology, Vol. 76, pp. 165-185 (1991).

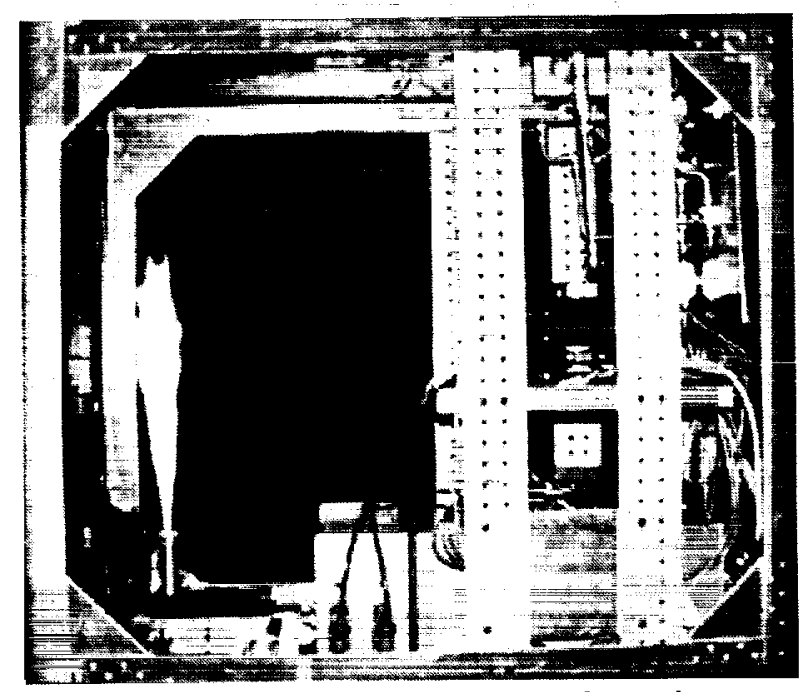

Figure 1. Photograph of the drop rig. 

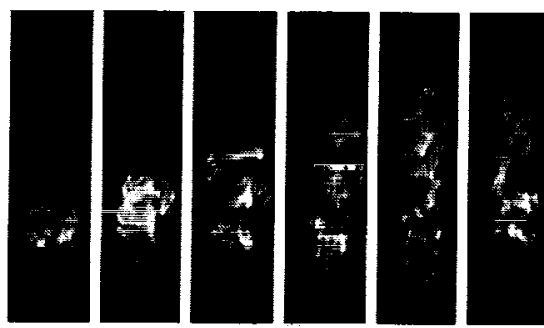

a) $\operatorname{Re}_{\mathrm{D}}=7500$, Low-gravity

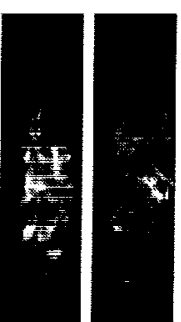

Figure 2. Time resolved sequence of emissit
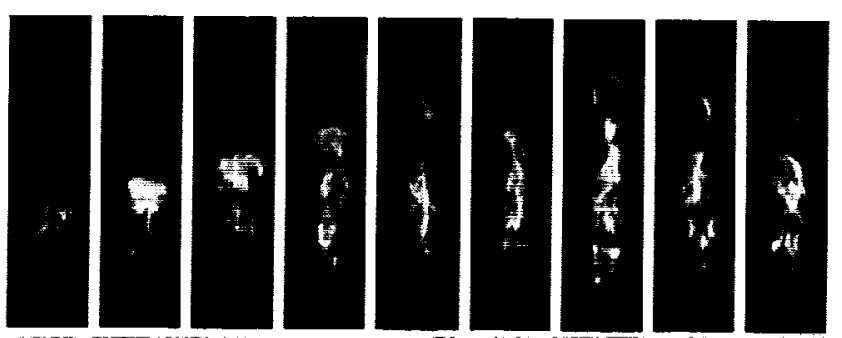

b) $\operatorname{Re}_{\mathrm{D}}=7500$, Normal-gravity
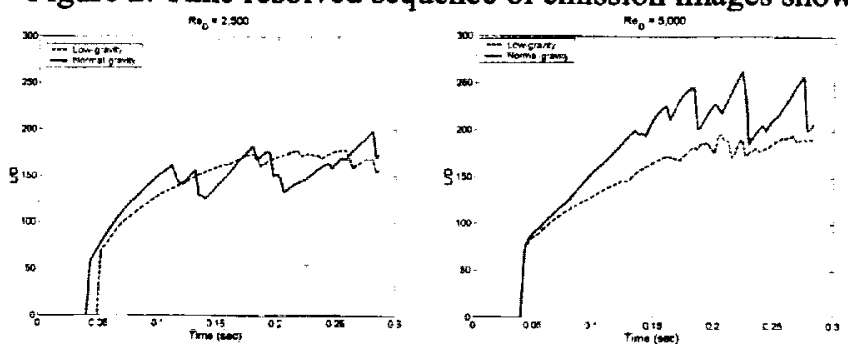

Figure 3. Flame tip variation with time for the various Reynolds numbers.
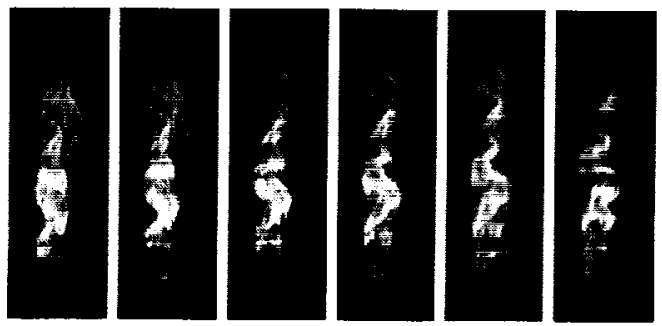

a) $\mathrm{Re}_{\mathrm{D}}=7500$, Low-gravity

Figure 4. Steady state sequences

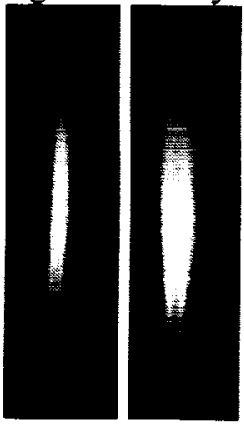

$\operatorname{Re}_{\mathrm{D}}=\mathbf{2 5 0 0}$

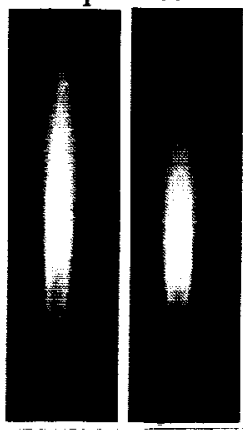

$\operatorname{Re}_{\mathrm{D}}=50 \overline{00}$

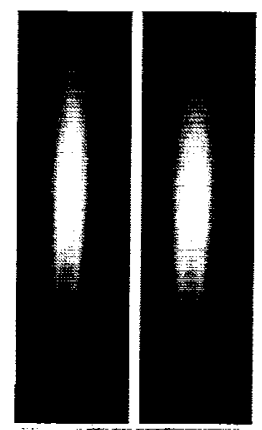

$\operatorname{Re}_{\mathrm{D}}=7500$
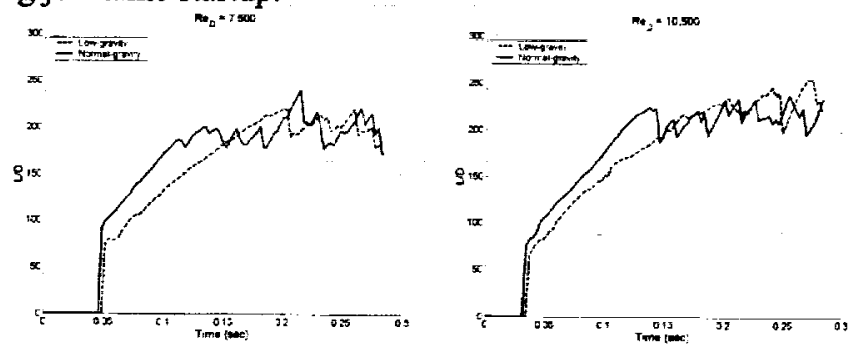

Figure 5. Average images obtained for different Reynolds numi .... In each pair normal-gravity image is to the left and low-gravity image is to the right.

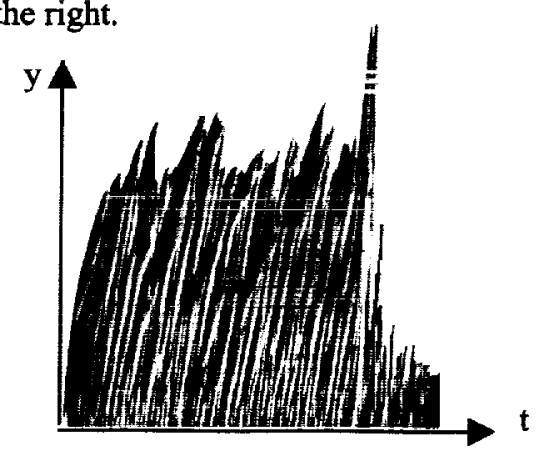

a) Low-gravity

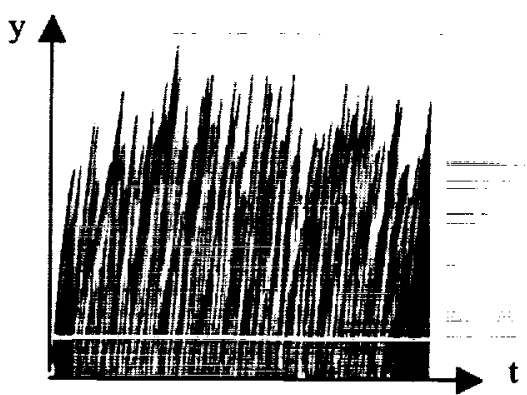

b) Normal-gravity
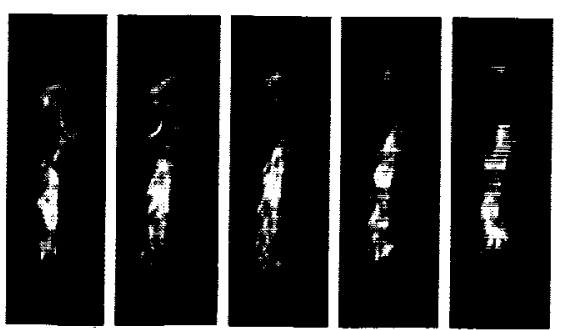

b) $\operatorname{Re}_{\mathrm{D}}=7500$, Normal-gravity

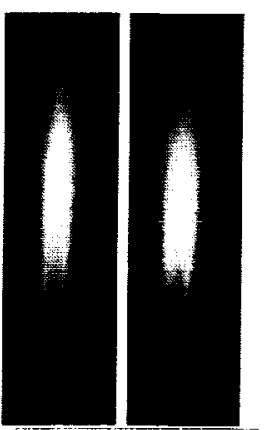

然
Figure 6. Variation of flame height with Reynolds number.

Figure 7. Sample volume renderings at $R e_{D}=2500$. 